\title{
MODERN MATHEMATICAL MODELS OF TIME \\ AND THEIR APPLICATIONS \\ TO PHYSICS AND COSMOLOGY
}

Proceedings of the International Conference held in Tucson, Arizona, 11-13 April, 1996

Edited by

W.G. TIFFT

Department of Astronomy, University of Arizona,

Tucson, Arizona, U.S.A.

and

W.J. COCKE

Department of Astronomy, University of Arizona,

Tucson, Arizona, U.S.A.

Reprinted from Astrophysics and Space Science

Volume 244, Nos. 1-2, 1996

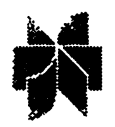

SPRINGER-SCIENCE+BUSINESS MEDIA, B.V. 
A C.I.P. Catalogue record for this book is available from the Library of Congress.

ISBN 978-94-010-6372-2 ISBN 978-94-011-5628-8 (eBook)

DOI 10.1007/978-94-011-5628-8

Printed on acid-free paper

All rights reserved

C)1997 Springer Science+Business Media Dordrecht Originally published by Kluwer Academic Publishers in 1997

Softcover reprint of the hardcover lst edition 1997

No part of the material protected by this copyright notice may be reproduced or utilized in any form or by any means, electronic or mechanical, including photocopying, recording or by any information storage and retrieval system, without written permission from the copyright owner. 


\section{TABLE OF CONTENTS}

Preface

\section{DAY 1 SESSIONS 1-3}

Session 1. The Redshift

HALTON ARP / The pair of X-ray sources across NGC 4258, its relation to intrinsic redshifts, ejection and quantization

JACK W. SULENTIC and J. BRETT SMITH / A fresh look at discordant redshift galaxies in compact groups

W.G. TIFFT / Evidence for quantized and variable redshifts in the cosmic background rest frame

W.M. NAPIER and B.N.G. GUTHRIE / Testing for quantized redshifts. I. The project

T.E. NORDGREN, Y. TERZIAN and E.E. SALPETER / The distribution of galaxy pair redshifts

Session 2. Critical Properties of the Universe

LI-ZHI FANG and YI-PENG JING / Density fluctuations on super-Hubble scales

S.A. GREGORY / The challenge of large-scale structure

ANTHONY L. PERATT / Electric space: evolution of the plasma universe

J.G. LAROS / Gamma-ray bursts: should cosmologists care?

\section{Session 3. Statistical Methods}

W.M. NAPIER and B.N.G. GUTHRIE/ Testing for quantized redshifts. II. The local supercluster 
W. COCKE, C. DEVITO and A. PITUCCO / Statistical analysis of the occurrence of periodicities in galaxy redshift data

P.A. STURROCK / Zooming in on the redshift problem

\section{DAY 2 SESSIONS 4-5}

Session 4. New Approaches to Cosmology

G. BURBIDGE / Two universes

JAYANT V. NARLIKAR / Anomalous redshifts and the variable mass hypothesis

W.G. TIFFT / Three-dimensional quantized time in cosmology

Session 5. Gravitation and Time in General Relativity

W.J. COCKE / The stress-energy tensor and the deflection of light in 6dimensional general relativity

P.C.W. DAVIES / Einstein's greatest mistake?

ROGER PENROSE / Time, space and complex geometry

D.F. ROSCOE / Discrete spatial scales in a fractal universe

TOM VAN FLANDERN / Possible new properties of gravity

LEOPOLD HALPERN / On the cosmic limits of physical laws

MENDEL SACHS / Changes in concepts of time from Aristotle to Einstein

METOD SANIGA / On the transmutation and annihilation of pencil-generated spacetime dimensions

\section{DAY 3 SESSIONS 6-7}

\section{Session 6. Nuclear and Particle Physics}

VINCENT ICKE / Particles, space and time

AVSHALOM C. ELITZUR / Time anisotropy and quantum measurement: Clues for transcending the geometrical picture of time

ARI LEHTO / 3-D Period doubling and magnetic moments of particles

C. WOLF/ Relics of the primordial origins of space and time in the low energy world

L.W. MORROW / Unexplained empirical relations among certain scatterings 
Session 7. Mathematical Models and Methods

CARL L. DEVITO / A Non-linear model for time $\quad 357$

W.M. STUCKEY / Defining spacetime 371

A.P. PITUCCO / Some elementary geometric aspects of extending the dimension of the space of instants 375

B.R. FRIEDEN / Fisher information as a measure of time 387 